\title{
Publisher Correction: Is DNA methylation the new guardian of the genome?
}

Robert M. Hoffman ${ }^{1,2}$

\section{Correction}

In the original publication of this article [1] the figures and the captions of 3 figures do not match correctly due to a typographical error. In this correction article the corrected figures and captions for Figs. 1, 2 and 3 are shown.

The publisher apologizes to the readers and authors for the inconvenience.

Received: 21 May 2018 Accepted: 22 May 2018

Published online: 13 June 2018

\section{Reference}

1. Hoffman RM. Mol Cytogenet. 2017;10(11) https://doi.org/10.1186/s13039-

017-0314-8. 

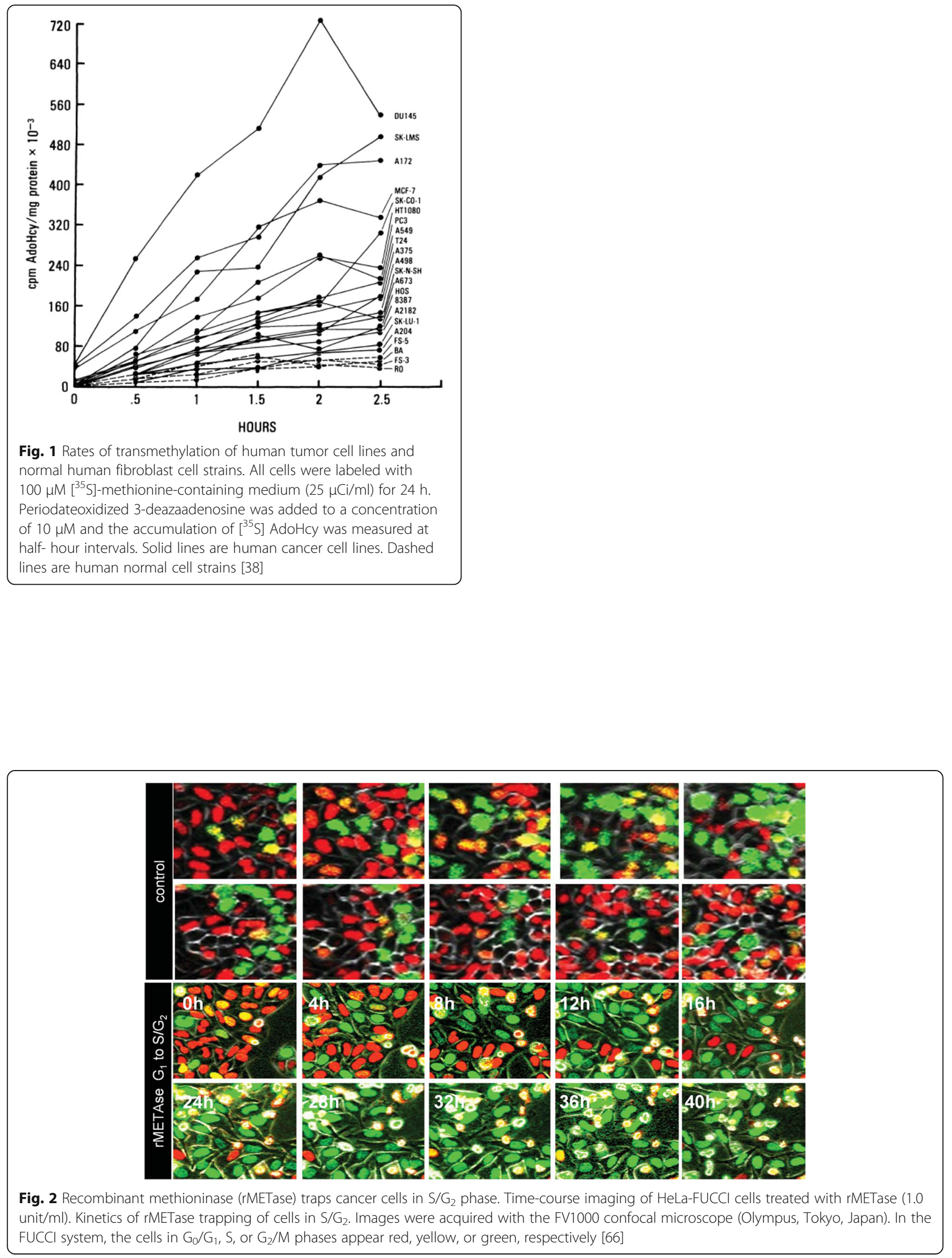


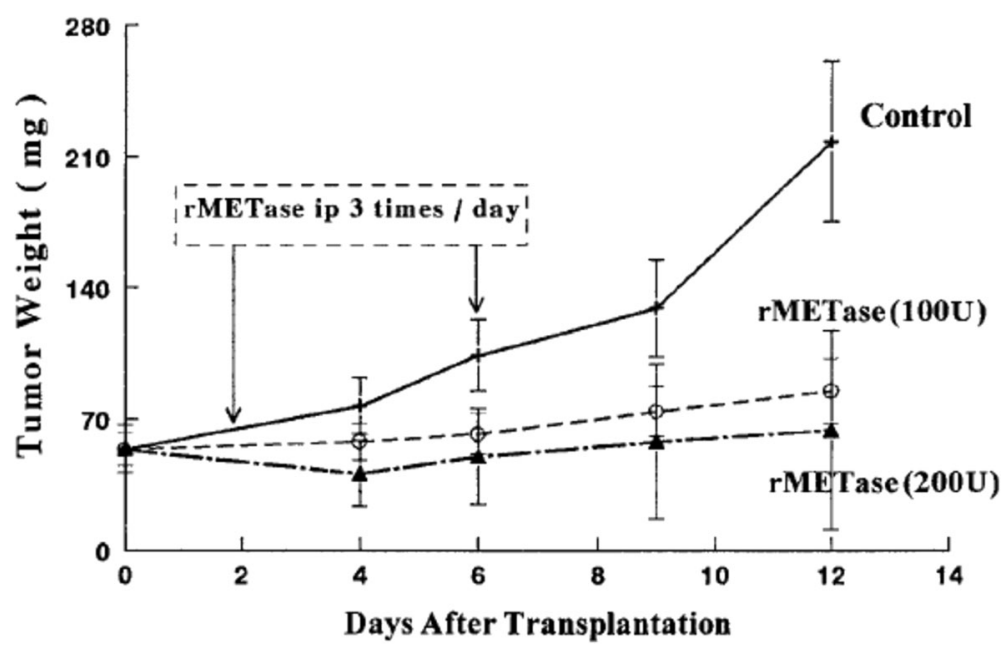

Fig. 3 Efficacy of recombinant methioninase (rMETase) on growth of human colon tumors HCT 15 in nude mice. rMETase (5 or 10 units/g every 8 h) was administered by i.p. injection in nude mice with human colon tumor HCT 15, growing s.c. [54] 